\title{
Efficacy of Non-Cytotoxic Doses of Some Medicinal Plant Extracts as Antibacterial and Anti-Biofilm Agents Against Cariogenic Bacterium Streptococcus mutans
}

\author{
Wael A. Elnaggar ${ }^{*}$, Tarek Hosny Taha ${ }^{2}$, \\ Nehal M El-Deeb ${ }^{3}$ and Hussam H. Arafat ${ }^{4,5}$ \\ ${ }^{1}$ Department of Health Sciences, Faculty of Pharmacy, Northern Border University, Rafha, KSA. \\ ${ }^{2}$ Department of Environmental Biotechnology, Genetic Engineering and Biotechnology Research \\ Institute (GEBRI), City of Scientific Research and Technology Applications \\ (SRTA- CITY), New Borg El-Arab, Alexandria, Egypt. \\ ${ }^{3}$ Department of Biopharmaceutical Product Research, Genetic Engineering and Biotechnology \\ Research Institute (GEBRI), City of Scientific Research and Technology Applications (SRTA- \\ CITY), New Borg El-Arab, Alexandria, Egypt. \\ ${ }^{4}$ Department of Biology, Faculty of Science and Arts, Northern Border University, Rafha, KSA. \\ ${ }^{5}$ Department of Botany and Microbiology, Faculty of Science, \\ Minia University, Minia City- 61519, Egypt.
}

http://dx.doi.org/10.13005/bbra/2163

(Received: 10 April 2016; accepted: 25 June 2016)

\begin{abstract}
Oral diseases are major health problems with dental caries and periodontal diseases among the most important preventable global infectious diseases. Increasing of refractory periodontal diseases is due to non-sensitivity of cariogenic bacteria to antibiotics, and the lack of new alternatives will be threat to danger imminent. This serious increase in the non-sensitivity of microbes to antibiotics may be opened to search for alternative approaches for exploring of new drugs with specific therapeutic activities. In this study cariogenic bacterium Streptococcus mutans strain ATCC 25175 was used as a test organism for evaluation the efficacy of water extracts of eight different medicinal plants as antibacterial and anti-biofilm agents. The best percentage of inhibition of these extracts against $S$. mutans strain ATCC 25175 was recorded as; Pomegranate peelÃ Cloveã Coffeee $\tilde{A}$ green tea. The cytotoxicity of the most potent extracts has been measured against fibroblast cells. Generally, the green tea extract was the safer extract followed by coffee, pomegranate peel and clove extracts. The recorded $\mathrm{IC}_{50}$ of the all used plant extracts on fibroblast cells ranged from $\mathbf{1 0 - 1 . 2 5 \%}$. with exception for green tea extract that didn't show IC $_{50}$ even with the maximum used concentration. The potency of the three selected extracts to to inhibt the biofilm formation by the tested strain could be summarized by the following order: pomegranate peelÃ coffeeÃ clove. Oral health influences the general quality of life and poor oral health is linked to chronic conditions and systemic diseases. Finally, give a recommendation for using some of these extracts to restrict the bacterial growth and reduction of the prevalence of periodontitis and cariogenic diseases.
\end{abstract}

Keywords: Oral diseases - Medicinal plants - Cytotoxicity - Antibacterial and anti-biofilm agents.

Dental caries are considered as one of the most prevalent oral infections affecting mankind worldwide. The initiation and progression

\footnotetext{
* To whom all correspondence should be addressed. Tel.: 00966566374523;

E-mail: t_tarek7946@yahoo.com
}

of this infection are mainly produced by endogenous oral bacterial species and their metabolites, including Streptococcus mutans, Streptococcus sobrinus and others ${ }^{1,2}$.

The acid producing $S$. mutans inhabiting the mouth causes damage by dissolving tooth 
structures in the presence of fermentable carbohydrates such as sucrose, fructose, and glucose $^{3}$. The food debris, acid, bacteria, and saliva combine in the mouth to form a sticky substance called "plaque" that adheres to the teeth. If plaque is not removed thoroughly and routinely, tooth decay will not only begin, but flourish ${ }^{4}$.

In addition, $S$. mutans produces glucosyltransferases (Gtfs) and synthesizes glucans from sucrose. Glucans are critical for bacterial accumulation on the tooth surface and the formation of cariogenic biofilms ${ }^{5}$. Furthermore, $S$. mutans survive at low $\mathrm{pH}$ values and generate acids that result in the deminer-alization of tooth enamel, thereby initiating dental caries ${ }^{6}$. Therefore, it has been proposed that disruption of the ability of $S$. mutans to form acids and glucans is an effective therapeutic approach for the treatment of dental caries ${ }^{7}$.

The limitation of this kind of oral infection might be achieved by using antimicrobial mouth rinses such as triclosan and chlorhexidine. The usual usage of these chemicals is limited for their undesirable side effects, including tooth staining, taste alteration and development of hypersensitivity reactions ${ }^{8,9}$. Antibiotics such as penicillin and erythromycin have been reported to effectively prevent dental caries in animals and humans, but they are never used clinically because of many adverse ${ }^{10}$ in addition to the development of bacterial resistance against them ${ }^{9}$. That is why there is a strong need for natural antibacterial alternatives. One of the potent alternatives are medicinal plants which could be traced as far back as the beginning of human civilization.

Medicinal plants are a source of great economic value all over the world ${ }^{11}$. Recent natural remedies with the use of medicinal plants, which are good reservoirs of chemotherapeutants can be, contributed as an alternative for antibiotic effects such as hypersensitivity reaction, supra infections, and teeth staining ${ }^{10}$. In addition, using of antibiotics for prevention of systemic infections originated from the oral cavity is not recommended because of the risk that bacteria will develop resistance to them. However, the discovery of extracts or oils of medicinal plants with antimicrobial and anti-inflammatory activity will be more safe and acceptable ${ }^{9}$.

The use of plants and plant products as medicines could be traced as far back as the beginning of human civilization. Medicinal plants are a source of great economic value all over the world ${ }^{11}$. Herbal medicine is still the mainstay of 75$80 \%$ of the whole population and the major part of traditional therapy involves the use of plant extract and their active constituents. Following the advent of modern medicine, herbal medicine suffered a setback, but during last two or three decades, advances in phytochemistry and in identification of plant compounds, effective against certain diseases have renewed the interest in herbal medicines ${ }^{12}$. In recent years, human pathogenic microorganisms have developed resistance in response to the indiscriminate use of commercial antimicrobial drugs commonly employed in the treatment of infectious diseases ${ }^{13}$.

The aim of this study was to evaluate the ability of calculated non-cytotoxic doses of different medicinal plants as new and natural alternatives to cease the growth of $S$. mutans strain with subsequent inhibition of its biofilm formation.

\section{MATERIALSAND METHODS}

\section{Bacterial Strain and Preservation}

Streptococcus mutans ATCC 25175, DSM No: 20523 reference strains were obtained from MERCIN, Faculty of Agriculture, Ain Shams University, Cairo, Egypt. The bacterial strain was preserved by adding 250 ì of $60 \%$ glycerol to $750 \mathrm{il}$ overnight LB culture and kept at $-80^{\circ} \mathrm{C}$.

\section{Preparation of Plants Extracts}

The suggested probable eight plants (Kari, Cinnamon, Coffee, Pomegranate peel, Clove, Green tea, Garlic and Ginger) were purchased from a local herbal market in Rafha governorate, Northern Border region, Saudi Arabia and were submitted to the standard extraction procedures according to Wendakoon et al. ${ }^{14}$ with some modifications. The obtained plants were washed three times using tap water, dried and 10 grams of each plant were submitted to extraction using $100 \mathrm{ml}$ of distilled water and boiled for $10 \mathrm{~min}$. The mixtures were then spun down at $3000 \mathrm{rpm}$ for $30 \mathrm{~min}$ and the obtained supernatants were kept at $4^{\circ} \mathrm{C}$ till use.

Determination of Antibacterial Activity and Minimum Inhibitory Concentration (MIC)

The antibacterial activity against Streptococcus mutans were tested and the 
minimum inhibitory concentration (MIC) was determined using descending concentrations of the each extract. The MIC of the eight plant extracts were diluted using sterile saline and were tested for their antibacterial activity against $S$. mutans. Each dilution was tested against nutrient broth inoculated media in microtiter plate. The plate was incubated at $30^{\circ} \mathrm{C}$ for $24 \mathrm{~h}$ and the optical density at $600 \mathrm{~nm}$ was measured using ELIZA reader.

\section{Cytotoxicity Assay}

Cytotoxicity assay was used for determination of the treatment concentration that does not have a toxic effect on normal cells. In this assay, human fibroblast cells were used as a normal cell modeling, a cell suspension of $6 \times 104 \mathrm{cell} / \mathrm{ml}$ was collected and seeded in 96-well plates (100 il cell suspension per well). The plates were incubated at $37^{\circ} \mathrm{C}$ in humidified $5 \% \mathrm{CO}_{2}$ for $24 \mathrm{~h}$. After obtaining a semi confluent cell layer, about 100 il of different treatment concentrations were incubated with cells at the previously described conditions for 3 days. After incubation, 100 il of neutral red stain was added to each well ${ }^{15}$, only living cells are permeable to neutral red and incorporated it into liposomes providing a quantitative assay to the cytotoxic effects. The stain intensity was assayed using automated ELIZA microplate reader adjusted at $540 \mathrm{~nm}$ (reference filters $620 \mathrm{~nm}$ ).

\section{Quantitative Assay of Biofilm Inhibition}

The ability of the plants extracts to inhibit biofilm formation of $S$. mutans was determined according to El-Adawi, 2012; with some modifications. In brief, triplicates of 100 ì of a previously prepared overnight bacterial culture in Luria broth were inoculated in 96-well flat-bottom Microtiter polystyrene plate with 50 ì of the nontoxic dose of the treatments. The plate was incubated for $48 \mathrm{~h}$ at $30^{\circ} \mathrm{C}$ without shaking. The plate was decanted once and followed by washing for three times with $200 \mathrm{iL}$ sterile PBS buffer. The plate was then dried at $60^{\circ} \mathrm{C}$ for $1 \mathrm{~h}$. The remaining biofilm was stained with $0.1 \%$ crystal violet for 15 min, decanted and washed three times with 200 iLof sterile distilled water. The plate was air dried for 15 min followed by the addition of $150 \mathrm{iL}$ of 95\% ethanol. The absorbance was measured at $570 \mathrm{~nm}$ using an ELISA assay plate reader. Untreated Streptococcus mutans strain was used as

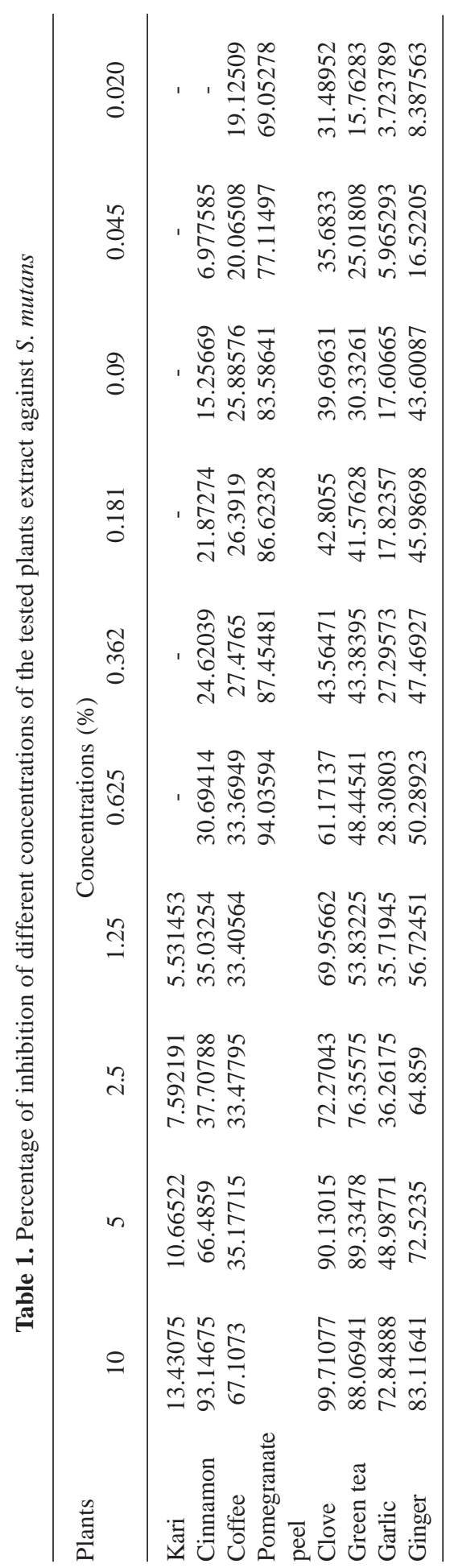


the positive control and un-inoculated LB broth as negative control.

\section{RESULTS}

\section{Determination of the MIC and antimicrobial activity of the tested extracts}

According to the examined plants; eight water extracts of the tested medicinal plants (Kari, Cinnamon, Coffee, Pomegranate peel, Clove, Green tea, Garlic and Ginger) were prepared and their different dilutions were tested for their antimicrobial activity against $S$. mutans using ELIZA reader equipment. The percentage of inhibition of each dilution was calculated and recorded (Table 1). Some of the tested dilutions showed a high percentage of inhibition at low concentrations of the extract. The best percentage of inhibition could be summarized as follows: Pomegranate peelÃ CloveÃ CoffeeeÃ green tea. The lowest obtained concentrations that have been recorded for these four medicinal plants could be submitted for more dilutions that can achieve more dilutions for the MIC. The minimum inhibitory

Table 2. Minimum inhibitory concentration (MIC) and percentage of inhibition for Kari, Cinnamon, Garlic and Ginger against $S$. mutans strain

\begin{tabular}{lcc}
\hline $\begin{array}{l}\text { Plant } \\
\text { Extracts }\end{array}$ & $\begin{array}{c}\text { Recorded MIC } \\
(\mathrm{g} / 100 \mathrm{ml})\end{array}$ & $\begin{array}{c}\text { Percentage of } \\
\text { inhibition (\%) }\end{array}$ \\
\hline Kari & 1.25 & 5.531453 \\
Cinnamon & 0.045 & 6.977585 \\
Garlic & 0.02 & 3.723789 \\
Ginger & 0.02 & 8.387563 \\
\hline
\end{tabular}

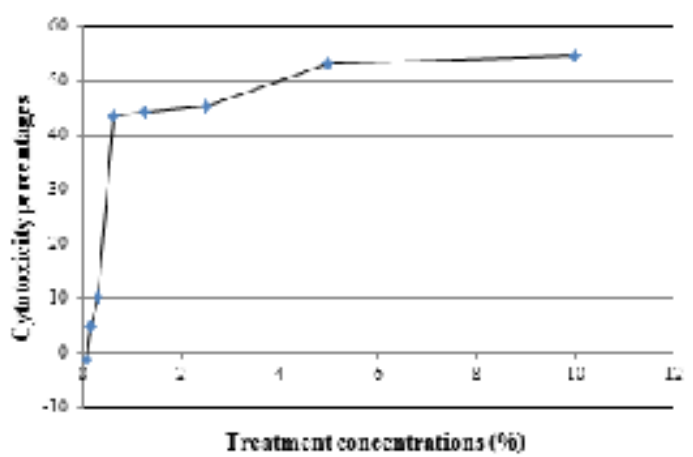

Fig. 2. Cytotoxicity of pomegranate peel extract against fibroplast cells with $\mathrm{IC}_{50}$ determination concentration (MIC) for most of the tested concentrations was also recorded (Table 2). The best percentage of inhibition was recorded as GingerÃ CinnamonÃ KariÃ Garlic.

\section{Cytotoxicity Determination of Some Selected Medicinal Plants}

The safety pattern of the most potent and selected plant extract was checked on fibroblast cells using neutral red assay protocol. The viability of the cells was quantitatively measured after $48 \mathrm{~h}$ of incubation. Generally, beginning with $10 \%$, the green tea extract was the safer plant extract (Figure 4) followed by coffee extract then both plant extracts (pomegranate peel and clove) as shown in figures 1,2 and 3 . The recorded IC $_{50}$ of the all used plant extracts on fibroblast cells ranged from 10$1.25 \%$ with exception for green tea extract that didn't show $\mathrm{IC}_{50}$ even with the maximum used concentration. By referring to the antibacterial results, the $\mathrm{IC}_{50}$ of plant extract pomegranate peel (2.5\%) exhibited antibacterial activities percentage over than 94.03.

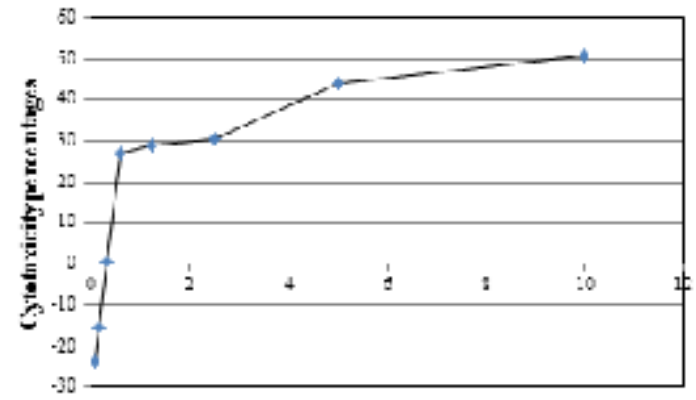

Treatmeat coucentrations (\%)

Fig. 1. Cytotoxicity of coffe extract against fibroplast cells with $\mathrm{IC}_{50}$ determination

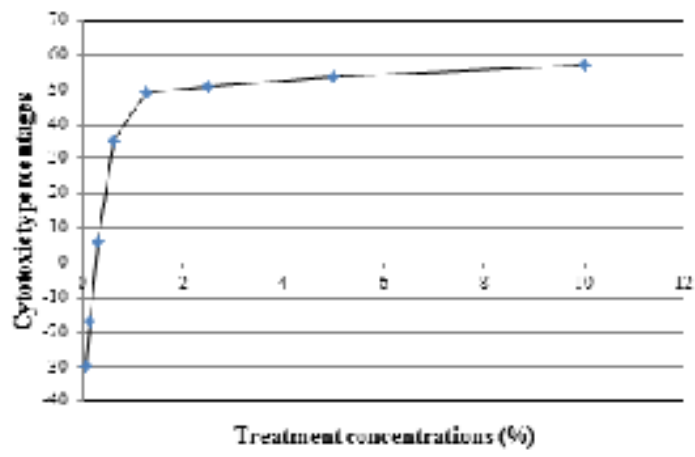

Fig. 3. Cytotoxicity of clove extract against fibroplast cells with $\mathrm{IC}_{50}$ determination 


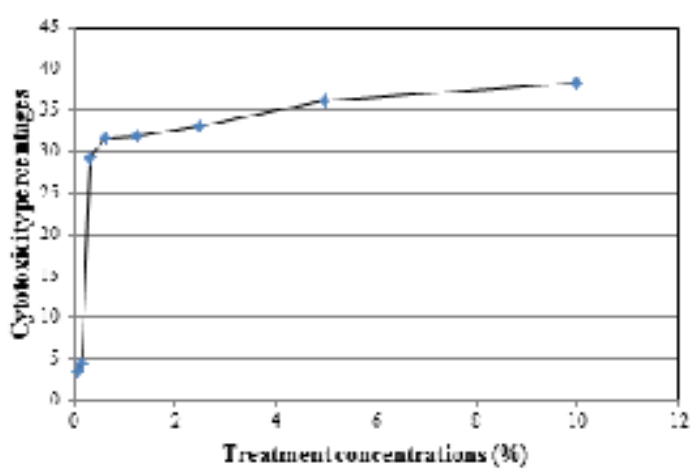

Fig. 4. Cytotoxicity of green tea extract against fibroplast cells with $\mathrm{IC}_{50}$ determination

\section{Inhibtion of Biofilm Formation Using Plant} Extracts

The MIC of three extracts that showed significant antibacterial activities have been selected for evaluation of their ability to inhibit the formation of biofilm by S. mutans. As shown in figure 5 , two extracts were able to inhibit the biofilm formation partially in a good way. Both of coffee and pomegranate peel succeeded to inhibt the biofilm formation by $S$. mutans by 30 and $43 \%$ respectively. On the other hand, clove has been failed to inhibit the biofilm formation by the tested strain. The potency of the three selected extracts to inhibit the formation of biofilm could be summarized by the following order: pomegranate peelÃ coffeeÃ clove.

\section{DISCUSSION}

Periodontal disease and dental caries are among the most common diseases in affecting mankind since the early history of ancient civilizations $^{16,17}$. At these time periods, people used medicinal plants as potent drugs for the treatment of these diseases. Since the discovery of penicillin, they have used antibiotics as alternatives for medicinal plants. The recent problems were arisen as a result of antibiotic resistance by many pathogenic microbes. Most of the recent drugs are depending on elimination of the bacterial pathogen by its destruction or prevention of biofilm formation ${ }^{18}$.

The results of the present study revealed that, the eight tested medicinal plants can cease

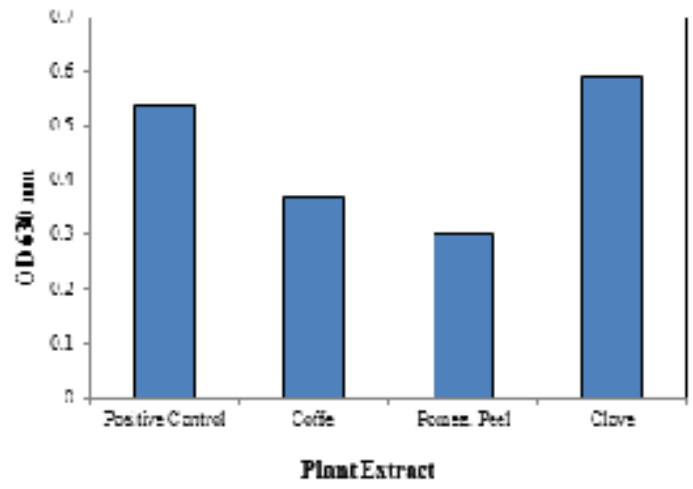

Fig. 5. Biofilm inhibition of $S$. mutans by the reported MIC of the three tested extracts, coffee, pomegranate peel and clove

the $S$. mutans growth efficiently. These individual extracts showed potent antibacterial activity against the cariogenic properties of $S$. mutans. This observation confirmed that these plant extracts possess bactericidal compounds, which inhibit a bacterial strain that is responsible for the growth of dental caries [19]. Sometimes, the combination between two or many extracts can exert a synergistic effect against the pathogen, which indicating more strong effect over single extract against the pathogen of interest $\mathrm{t}^{20}$.

As time is passing, the microbes have modern potentials to resist antibiotics and antimicrobial agents. Modern research in microbiological field is recently concerned with the development of the natural sources for management of diseases and in particular, oral diseases. The elimination of the bacteria that cause oral diseases is mainley depending on its destruction or prevent the formation of biofilm, which is crucial for its existence ${ }^{18}$.

The concept of biofilm destruction by the chosen medicinal plant lead us to examine the best recorded MIC of the extracts to inhibit the formation of biofilm by S.mutans. As shown in figure 5, two of the three examined extracts showed almost 30 and $43 \%$ of inhibition for coffee and pomegranate peel respectively, compared with the positive control (S. mutans with no additions). The cytotoxicity results revealed that the recorded MIC for the three selected extracts is safe on human fibroblast cells. The most safer one was coffee followed by pomegranate peel and clove. These results emphasis that the extracts could be used 
as antimicrobial agents against $S$. mutans with safe effect to human cells.

\section{CONCLUSION}

The obtained results revealed that medicinal plants are considered as potent alternatives for antibiotics for the treatment of bacterial infections with studied and calculated MIC that can harm the bacterial units without cytotoxic effect against the human cells. We could recommend the preparation of a triple mixture of clove, pomegranate peel and coffee as a mouth wash for the treatment of caries causing agent with safety issue.

\section{ACKNOWLEDGEMENT}

Wael A. Elnaggar, Tarek Hosny Taha, Nehal M. El-Deeb and Hussam H. Arafat are supported with the research grant No (5/1436/6/3), Deanship of Scientific Research, Northern Border University, Arar, KSA.

\section{REFERENCES}

1. Socransky, S.S., Haffajee, A.D. Periodontal microbial ecology. Periodontol 2000, 2005; 38: $135-187$.

2. Tanzer, J.M., Livingston, J., Thompson, A.M. The microbiology of primary dental caries in humans. J. Dent. Educ., 2001; 65: 1028 - 1037.

3. Kleinberg, I. A mixed-bacteria ecological approach to understanding the role of the oral bacteria in dental caries causation: an alternative to Streptococcus mutans and the specific-plaque hypothesis. Crit. Rev. Oral Biol. Med., 2002; 13(2): 108-125.

4. Hardie, J.M. Oral microbiology: current concepts in the microbiology of dental caries and periodontal disease. Br. Dent. J., 1992; 172(7): 271-281.

5. Hamada, S., Slade, H.D. Biology, immunology and cariogenicity of Streptococcus mutans. Microbiol. Rev., 1980; 44: 331 - 384.

6. Belli, W.A., Marquis, R.E. Adaptation of Streptococcus mutans and Enterococcus hirae to acid stress in continuous culture. Appl. Environ. Microbiol., 1991; 57: 1134 - 1138.

7. Xu, J., Li, Y., Cao, X., Cui, Y. The effect of eugenol on the cariogenic properties of Streptococcus mutans and dental caries development in rats. Exp. Ther. Med., 2013; 5:
1667 - 1670.

8. Baca, P., Clavero, J., Baca, A.P., GonzálezRodríguez, M.P., Bravo, M., Valderrama, M.J. Effect of chlorhexidine-thymol varnish on root caries in a geriatric population: a randomized double-blind clinical trial. J. Dent., 2009; 37: $679-685$.

9. Fani, M., Kohanteb, J. Inhibitory activity of Aloe vera gel on some clinically isolated cariogenic and periodontopathic bacteria. J. Oral Sci., 2012; 54(1): 15 - 21.

10. Jebashree, H.S., Kingsley, S.J., Sathish, E.S. and Devapriya, D. Antimicrobial activity of few medicinal plants against clinically isolated human cariogenic pathogens-an in vitro study. ISRN Dent., 2011:541421.

11. Ahmed, L., Mohammed, Z., Mohammed, F. Screening of some Indian medicinal plants for their antimicrobial properties. $J$. Ethnopharmacol., 1998; 62: 183 - 193.

12. Arora, D., Kaur, J. Antimicrobial activity of spices. Int. J. Antimicrob. Ag., 1999; 12: 257 262.

13. Mohammed, N.A. Effect of Nigella Sativa L. extracts against Streptococcus mutans and Streptococcus mitis in Vitro. J. Bagh. Coll. Dent., 2012; 24(3): 154 - 157.

14. Wendakoon, C., Calderon, P., Gagnon, D. Evaluation of selected medicinal plants extracted in different ethanol concentrations for antibacterial activity against human pathogens. J. Med. Active Plants, 2012; 1: 60 - 68.

15. Borenfreund, E., Puerner, J.A. Toxicity determined in vitro by morphological alterations and neutral red absorption. Toxicol. Lett., 1985; 24: 119 - 124 .

16. Forrai J. Culture history of dentistry. Dental Press Budapest. 2005; 84 - 113.

17. Forrai, J. The beginnings of dental caries and its treatments. Rev. Clin. Pesq. Odontol., Curitiba., 2009; 5: 187 - 192.

18. Al-Rowais, N.A. Herbal medicine in the treatment of diabetes mellitus. Saudi Med. J., 2002; 23: 1327 - 31.

19. Dinesh, M.D., Uma, M.S., Anjali, V.M., Neetushree, Meenatchisundaram, S., Shanmugam, V. Inhibitory properties of aqueous extracts of selected indigenous medicinal plants against dental caries causing Streptococcus mutans and Streptococcus mitis. African J. Basic Appl. Sci., 2013; 5(1): $08-11$.

20. Hamad, G.M., Taha, T.H., El-Deeb, N.M., Alshehri, A.M. Advanced trends in controlling Helicobacter pylori infections using functional and therapeutically supplements in baby milk. J. Food Sci. Technol., 2015; 52(12): 8156-8163. 